\title{
MUJERES ANTES, DURANTE Y DESPUÉS DE LA GUERRA DE INDEPENDENCIA: EL CASO DE DOMINGA ORTIZ Y JOSEFA CAMEJO
}

\author{
Violeta Rojo \\ Universidad de Simón Bolívar (Venezuela)
}

\section{RESUMEN}

El aporte de las mujeres a la sociedad venezolana antes, durante y después de la Guerra de Independencia, fue muy importante, pero ha sido soslayado por el discurso historiográfico tradicional. A través de las actuaciones de Dominga Ortiz y Josefa Camejo es posible mostrar cual fue la actuación femenina de esos años en los aspectos sociales, educativos, económicos y militares. También, cómo el discurso anterior, en el que se negaba su participación es tan manipulador como el actual, en el que sólo se muestran sus hazañas guerreras y olvidan su aporte como civiles a la construcción de la sociedad.

Palabras clave: mujeres, heroínas, Guerra de Independencia venezolana, manipulación del discurso histórico.

\section{ABSTRACT}

The very important contribution of venezuelan women to their society before, during and after the war of independence has not been fully recognized by most historians. The relevant roles played during that process by Dominga Ortiz and Josefa Camejo, covering a rich variety of its social, educational, economic and military aspects, clearly shows how decisive their contributions were - not only to the war effort- but also to the building of the new nation and to the strengthening of the civilian character of its society.

Key words: women, heroines, Venezuelan war of independence, manipulation of the historic discourse.

El objetivo de este trabajo es analizar el papel de las mujeres vinculadas a la Guerra de Independencia venezolana y el discurso sobre el mismo. Pero no sólo lo que hicieron en la pelea (y cómo fue percibido, recibido y manipulado) sino también lo que pasó antes y después. Creo que se han creado una serie de mitos y fabulaciones sobre los que fueron las mujeres de esos años, ocultándolas de tal manera bajo las máscaras del deber ser, de los deseos frustrados, o de lo que se quería demostrar, que 
ya poca idea tenemos que lo que realmente fueron e hicieron. Los discursos, tanto el machista como el feminista, estamos olvidan la realidad de estas mujeres.

Las latinoamericanas del siglo XIX estuvieron fuera de la Historia por decenas de años. Durante su vida fueron despreciadas; mientras se construían las naciones se las consideró pasivas, ignorantes e incapaces de cumplir otro papel que el de abnegadas madres y esposas. Actualmente está siendo aceptada y difundida su activa participación en eventos primordiales de la independencia, pero mucho me temo que el reconocimiento que reciben no sea el más importante, y que nuevamente se esté olvidando que ellas, de forma callada e incansable, construyeron nuestros países.

Para hablar de la época es conveniente que olvidemos el lugar común de las mujeres apáticas y sin autonomía, que no sabían qué pasaba fuera de las puertas del hogar. Por ejemplo, Manuel Rodríguez Campos las describe diciendo que habían nacido

en una sociedad organizada por los hombres, de quieres estaban subordinadas, las de mediano y alto rango económico habían conocido un mundo donde las contrariedades mayores eran las de la vida cotidiana. Los quebrantos de su tranquilidad raras veces alcanzarían más allá de los que se referían a la convivencia hogareña; acaso algún contratiempo económico sufrido por el cabeza de familia, si es que lo comunicaba a las mujeres de la casa ${ }^{1}$

La condescendiente versión de Rodríguez Campos podría ser ratificada por la visión de un viajero, Semple, que estuvo en Venezuela en los tiempos de la Primera República y dice:

La principal ocupación matinal de las mujeres es su asistencia a misa, ataviadas de negro y tocadas con mantilla, luciendo medias de seda y coqueteando con el abanico que siempre llevan en constante movimiento ${ }^{2}$

Esta visión de mujeres "recogidas" para usar el término de la época y que significa que viven retiradas en sus casas, contrasta con lo que se lee en la prensa de esos años. Al revisar la Gaceta de Caracas es normal ver anuncios en los que mujeres venden casas de habitación y haciendas de cacao, café, caña o hatos de ganado, participan la fuga de esclavos o, ya en los años del conflicto, donan dinero a uno u otro bando. En la misma Gaceta, en 1816 hay una lista de personas por profesión, gracias a ella podemos saber que había mujeres mercaderes, propietarias de casas, hacendadas, comerciantes y bodegueras. Las mujeres de todas las clases sociales participaban en el trabajo. Charles Brown, en su Relato de la expedición salida de Inglaterra a fines de 1817, para el servicio de los patriotas españoles... indica que los obreros que construían casas en Margarita en 1818 eran hombres y mujeres ${ }^{3}$. Había mujeres como Doña Felipa de Linares y Torrellas de El Tocuyo, que en su testamento declaró poseer una amplia biblioteca ${ }^{4}$, y en el siglo XVIII hubo cantidad de mujeres artesanas: pintoras, escultoras, plateras, bordadoras $^{5}$. Otras hacían granjerías, tapetes y alfombras; o eran enfermeras, curanderas y comadronas; panaderas; agricultoras; servicio doméstico, actrices de teatro y bailarinas ${ }^{6}$.

A pesar de que toda la legislación estaba en su contra, y eran pocos los derechos que tenían ${ }^{7}$, eso no las amilanaba para actuar como iguales. Eso puede verse en los innumerables juicios que entablaban

\footnotetext{
RODRÍGUEZ CAMPOS, Manuel. "La mujer en la economía venezolana del siglo XIX”. En: La mujer en la historia de Venezuela. Caracas: Asociación civil La mujer y el quinto centenario de América y Venezuela, 1995, p. 329

SEMPLE/DELPECH/POUDENX Y MAYER. Tres testigos europeos de la Primera República (1808-1814). Caracas: Ediciones de la Presidencia de la República, 1974, p. 30

HACKETT, James y Charles Brown. Narraciones de dos expedicionarios británicos de la independencia. Caracas: Instituto Nacional de Hipódromos, 1966, p. 187

4 TROCONIS DE VERACOECHEA, Ermila (1990) Indias, esclavas, mantuanas y primeras damas. Caracas: Alfadil/Academia Nacional de la Historia, p. 39

$5 \quad$ Ibíd, 104-105

6 ALVAREZ DE LOVERA, María (1994) La mujer en la colonia. Situación social y jurídica. Caracas: Fondo Editorial Tropycos/ FACES-UCV.

Sobre el tema, ver PONCE, Marianela: De la soltería a la viudez. La condición jurídica de la mujer en la Provincia de Venezuela en razón de su estado civil. Estudio preliminar y selección de textos legales. Caracas: Biblioteca de la Academia Nacional de la Historia, 1999.
} 
las mujeres, como han demostrado Ma. Dolores Fuentes Bajo y Frédérique Lange en sus excelentes artículos sobre las Nueve Musas, las hermanas Jerez de Aristiguieta ${ }^{8}$.

En los epistolarios de esos años, es también evidente que las mujeres piensan y opinan sobre aspectos políticos. Así, hay cartas donde Monseñor Coll y Prat se muestra indignado por la participación de las mujeres en la Sociedad Patriótica

...pues no pueden comprender nada de filosofemas, ni de revoluciones políticas, ni de lectura de rudimentos...

...Para entender que las cosas andan mal, baste verlas metidas en retórica con libros en la mano, opinionando y hablando en las tertulias (...) Mujeres opinando lo que no pueden saber, pueblo sufriendo?.

Como es sabido, también hubo mujeres participando en el gobierno. A partir de 1526 hubo tres generaciones de mujeres, las Manrique, como gobernadoras de Margarita. Cuando una de las mujeres se casaba le daban al hombre la gobernación en los papeles; pero cada vez que enviudaban se hacían cargo del gobierno de la isla, la organizaban y la defendían, sin que sus encomendados protestaran. Igual que las Manrique también tenemos a Leonor Cáceres, defensora de Caraballeda ante el ataque de los Caribes. En 1781, cuando comienza el Movimiento Comunero de Maracaibo y se dan una serie de protestas contra el gobierno español por los altos impuestos y el monopolio en el ron y el tabaco, son mujeres (Salvadora Chacón, Antonia González, Bernardina Alarcón y Rafaela Pineda) las que más protestan. Y durante los eventos de los Comuneros de Mérida en 1787, las mujeres firman un memorial.

Ya durante los años de la guerra de independencia, la participación femenina fue amplia y efectiva. Sus acciones podrían dividirse en distintos tipos. Están las que apoyaban a sus esposos en la rebelión, los escondían y cuidaban (Josefa Joaquina Sánchez, Ma. Josefa Torres), las que los acompañaban en las batallas (Eulalia Ramos, Dolores Jerez). Algunas actuaron activamente como espías e informantes (Consuelo Fernández), guerreras (Concepción Mariño; Concepción y Mercedes Ribas, "que acompañadas de sus esclavas y de mujeres adictas solían (...) lanzarse (...) y pelar a las más odiadas familias godas; eran verdaderos combates de mujeres..."10. Otras fueron enfermeras (Dominga Ortiz), proporcionaron dinero y bestias, dieron sus joyas y sus tierras (Josefa Figueras, entre muchas otras), pelearon en el campo de batalla (Bárbara de la Torre, Rosa Canelones, Manuela Tinoco) y en la estrategia (Josefa Arestiguieta y Lovera), hicieron grupos conspirativos (Juana Padrón, Josefa Palacios, Luisa Arrámbide) y se pusieron al frente a los ejércitos (Josefa Camejo, Juana Ramírez). Están también las que se mantuvieran activamente al lado del Rey de España, las que no querían que la corona abandonara las tierras venezolanas (Micaela Longa, Ma. Antonia Bolívar) ${ }^{11}$.

Por supuesto, también hubo víctimas. Todas las mujeres de esa época vieron morir a los suyos, perdieron sus bienes, cambiaron de vida y pasaron terribles miserias. Además, estuvieron las que fueron duramente castigadas por opinar, llegando a ser azotadas (Ana María Campos, Domitila Flores), torturadas (Teresa Heredia, Leonor Guerra), encarceladas (hermanas Guevara: Soledad, Catalina, Lucía y María), expulsadas (Josefa Antonia Tovar de Buroz, Manuela Arestiguieta de Zárraga) y muertas (incontables) por expresar sus ideas. También están las que fueron heridas o fallecieron en las batallas, ya fuera porque participaron en ellas o porque estaban en las cercanías. Hubo también troperas, aunque ambos ejércitos lo prohibían.

\footnotetext{
LANGE, Frédérique. "El honor es una pasión honrosa. Vivencias femeninas e imaginario criollo en Venezuela colonial". En: Anuario de Estudios Bolivarianos, 7-8. Caracas, Universidad Simón Bolívar, 1998-1999. FUENTES BAJO, Ma. Dolores. "Familia, matrimonio y poder en la Caracas colonial: el caso de los Jerez de Aristeguieta, 1786-1809". Ponencia en el IX Congreso Internacional de Historia de América. Asociación de Historiadores Latinoamericanistas Europeos (AHILA). Sevilla, 1992.

9 PINO ITURRIETA, Elías (1993) Ventaneras y castas, diabólicas y honestas. Caracas: Planeta, p. 35

10 "Cartas de mujeres". Boletín Academia Nacional de la Historia, 62. Caracas, 1933

11 Sobre el tema han escrito: CHERPAK, Evelyn. "Las mujeres en la Independencia. Sus acciones y contribuciones". En: VELÁSQUEZ, Magdala. Las mujeres en la historia de Colombia. Bogotá: Norma, 1995 y ROJO, Violeta: "De la dama sumisa a la mujer aguerrida: Ser y deber ser en las venezolanas de principios del siglo XIX". En: Anuario de Estudios Bolivarianos, Año XI, $\mathrm{N}^{\circ}$ 12. Bolivarium USB, 2005 y "Luisa Cáceres de Arismendi ¿heroína? de la guerra de independencia". En: Revista Venezolana de Estudios de la Mujer, 8, 21, UCV, 2003.
} 
Doy esta larga lista de mujeres por una razón simple. Hasta hace muy poco, en los libros de historia ellas y sus hechos no existieron. Quizás un breve comentario sobre su condición de "varonas". A partir de ciertos libros, se puede pensar que durante la guerra de independencia, Venezuela era un país habitado sólo por hombres.

De las mujeres que participaron en la guerra quiero detenerme en dos: Dominga Ortiz y Josefa Camejo. Ambas tuvieron muchas actividades en la guerra, ambas son conocidas y admiradas.

Dominga Ortiz (1792-1875) era una muchacha de Canaguá, Barinas, que quedó huérfana muy joven. Heredó de sus padres un hato importante y a los 17 años se casó con José Antonio Páez, que en esa época trabajaba con ganado. Al año de matrimonio, Páez se alista en el ejército patriota donde gana el renombre que todos conocemos. Dominga, de quien algunos dicen que tenía cierta educación, era una mujer rica, dueña de tierras y ganado de los que se había ocupado desde siempre. Ella lo acompaña en las batallas y tiene dos hijos en el ínterin. En 1816 organizó un grupo de enfermeras para atender a los heridos. Los soldados la querían mucho y la llamaban La Señora. Dominga vuelve a su hato y trata de reconstruir la hacienda, destruida por la guerra y levanta a sus hijos. En una serie de episodios por todos conocidos, después de la guerra, Páez se dedica a Barbarita Nieves. Barbarita muere y Páez es enviado a prisión. Dominga va a Cumaná en 1848, donde él estaba preso para cuidarlo, aunque algunos dicen que en realidad estaba aprovechando la situación para hacerle la vida imposible ya que allí él no se podía escapar de ella. Consigue que se firme la liberación y lo acompaña hasta Saint Thomas, desde donde vuelve a su hacienda. Dominga Ortiz era una dedicada mujer de negocios, pero la caída en desgracia de Páez la convierte en blanco de una serie de problemas legales. Ella siempre había sido muy activa en los tribunales peleando por sus bienes y siempre lo hacía a título personal, sin embargo, a partir de los cambios políticos pierde mucho dinero que nunca más recuperó. El gobernador de Barinas ordenó encarcelarla y ella se tiene que ir a Valencia.

Aunque ha sido considerada por los recuentos históricos más conservadores como una matrona que, a pesar del evidente adulterio del marido, se mantuvo digna y cumplió con sus sagrados deberes de esposa cuando él lo requirió, una carta en la que le cuenta todo lo que ha sucedido con los bienes de la familia, muestra entre ellos un compañerismo encantador. En ella habla de la hostilidad de los banqueros, que "nos precipitaron indudablemente á la miseria mas espantosa, pues nunca acabaremos de pagar", se queja de los "fingidos amigos" que se van a quedar con "el fruto de tantos trabajos, de tantas privaciones como habremos tenido para poner esa finca en el estado en que está":

Te confiaré pues mi situación, y esperaré tus consejas, que acogeré gustosa. Ya ves que nada se coge de la casa de Pto. Cabello; en este sábado la he mandado a desocupar, quien sabe si no la dan. Los hatos enteramente destruidos, no hay más que sabanas; la casa de Valencia en tan mal estado, que ya el corredor frente a la puerta de la sala se cayó y así se haya toda ella (...) figúrate, después de haber vendido hasta la última prendesita, y de prestado (...) hoy mismo ya he vendido también las pocas prendas que le quedaban a Maria del Rosario. Yo no sé que se irá que hacer, ya no tengo a quien pedirle ni quien me preste y ya José Antonio le confieso estoy cansada de llevar cuentas, mucho más, tan enferma como me hallo (...) espero me digas si me deja vender la finca, vendiéndosela al Banco o qué hago; espero tu contestación para resolver ${ }^{12}$.

Sin embargo, el 7 de noviembre del mismo año, se introduce en el Registro Principal una lista de bienes de Páez, por "Juan Valero, apoderado de la señora Dominga Ortiz de Páez, como mujer legítima del señor general José Antonio Páez, solicitando la división de los bienes conyugales en el matrimonio con éste"13. Dichos bienes incluían tres hatos, cuatro terrenos, algunos con ganado; una isla, seis casas, dos haciendas de café, un ingenio de caña, y un solar en Caracas. Según los libros, Dominga murió en la miseria, pero peleó sus bienes hasta el final.

12 De Dominga Ortiz de Paez a José Antonio Paez. 26 de noviembre de 1849

13 PINTO, Manuel (Compilación, selección y notas) Documentos para la historia de la vida de José Antonio Páez. Caracas: Ediciones del Congreso de la República, 1976, p. 318 
Su situación económica llega a ser tan terrible, que se ve obligada a publicar un Remitido en La Opinión Nacional (6 de febrero de 1874) en el que utiliza el nombre del marido y se hace ver como desvalida:

Entiéndase bien, señores diputados, que educada en la escuela del infortunio, no reclamo un derecho adquirido por la ley, sino que humilde como cumple a mi sexo y mi edad, imploro en nombre del General José Antonio Páez, ciudadano esclarecido de Venezuela, una limosna"14

Como vemos, fue una emprendedora antes, durante y después de la guerra que se ocupó de mucho más que de las labores propias de su sexo.

Otro tanto sucede con Josefa Camejo. Esta paraguanera nació en Curaidebo, Falcón en 1791 y murió en Maracaibo en 1870. Aunque es conocida como la libertadora de Coro, hizo muchas cosas más. Era una mujer educada, que estudió en el Colegio de Monjas de la Salceda en Coro y luego en el Convento de Monjas Concepcionistas de Caracas. Entre las materias que recibió estaba aritmética, historia sagrada, religión, labores manuales y música ${ }^{15}$ gramática y geografía ${ }^{16}$. En 1810 está en Caracas durante los sucesos del 19 de abril y comienza a interesarse por el concepto de república. En 1811 se muda a Barinas, allí firmó un documento fundamental, la Representación que hace el bello sexo al Gobierno de Barinas (5 de noviembre de 1811), en el que un grupo de mujeres se ofrecen para defender la ciudad

El sexo femenino, Señor, no teme los horrores de la guerra: el estallido del cañón no hará más que alentarle: su fuego encenderá el deseo de libertad, que sostendrá a toda costa en obsequio del suelo Patrio. En esa virtud y deseando alistarse en el servicio para suplir el defecto de los militares que han partido a San Fernando, suplican a V.E. se sirva tenerlas presente y destinarlas a donde le parezca conveniente baxo el supuesto de que no omitirán sacrificios que conciernan a la seguridad y defensa. ${ }^{17}$

Se casa con Juan Nepomuceno Briceño Méndez, profesor de filosofía en la universidad que se había incorporado a la lucha patriota. Por distintos eventos de la guerra Josefa debe emigrar a Nueva Granada, donde da a luz a su hijo Wenceslao (que será un geógrafo y geólogo importante. Luego tuvo a Teotiste). En las Memorias de O'Leary se dice:

Tres mujeres, no más, salieron vestidas de hombres y a hurtadillas, en las filas: éstas fueron Josefa Camejo, cuyo marido estaba allí; la hermana de los capitanes Canelones y la mujer de un tal Valbuena, llamada Manuela Tinoco: siguieron hacia el reino [Nueva Granada] ${ }^{18}$

En 1821, también según O’Leary, mientras está con las tropas de Urdaneta, "capitaneó una escolta de 15 hombres con la misma autoridad que un general" ${ }^{19}$. Permanece cuatro años en Nueva Granada, decide regresar a Venezuela disfrazada de mendiga, su idea era llegar a sus tierras en la península de Paraguaná y atacar a los realistas asentados en Coro. Cuando llega comienza a organizar sus contactos. Aparentemente conspiraba a alto nivel con su tío el Padre Mariano Talavera y Garcés y Rafael Urdaneta. En 1821 reúne 300 hombres, además de caballos y pertrechos y se enfrenta a los realistas. El ejército de Josefa es derrotado, pero días después derrota al jefe realista Chepito González y encarcela al gobernador, nombrando a uno civil y republicano.

\footnotetext{
14 GUERRERO, Luis Beltrán. “Oración del centenario”. En: Centenario de la muerte del general José Antonio Páez (1873-1973). Discursos. Caracas: Ediciones de la Presidencia de la República, 1973, p. 64

15 TROCONIS DE VERACOECHEA, Ermila (1992) "Josefa Camejo: una mujer en la historia. En: Boletín Academia Nacional de la Historia, 297. Enero-marzo, p. 25

16 ESTEVES, Juan C. La heroína Josefa Camejo. Coro: Maraven, 1989, p. 15

17 Gaceta de Caracas, 5/11/1811

18 Tomo IV, p. 320. En: TROCONIS DE VERACOECHEA, Ermila. "Josefa Camejo: una mujer en la historia. En: Boletín Academia Nacional de la Historia, 297. Enero-marzo 1992, p. 25.
} 
Además, escribe la proclama, que reza:

Corianos! Es una satisfacción para la República de Colombia, llamaros sus hijos: vuestra conducta en este último período, es conforme a lo que debéis a vuestra Patria y a vosotros mismos. Yo os felicito por el buen uso que habéis hecho de vuestro celo y valor y me prometo que en lo futuro seréis los más fieles republicanos.

Corianos! Nombrad vuestros representantes en el Congreso Nacional: allí seréis soberanos de Colombia, y en vuestro suelo seréis los ciudadanos más libres, protegidos por las leyes que dictan vuestras conciencias y voluntad.

Todos corianos, sois iguales en Colombia, como en España todos erais desiguales; a todos dividían barreras odiosas con privilegios inicuos y degradaciones absurdas.

Esta es la República de Colombia: ella sin duda penetrará en vuestros corazones y se colocará en vuestro amor porque ella es Madre y todos son sus hijos. ${ }^{20}$

Después de la independencia vuelve a ocuparse de sus haciendas, enviuda y luego se casa nuevamente, esta vez con el Dr. José Bracho, médico. El segundo matrimonio no funciona, así que abandona a su marido.

Anteriormente la gran heroína venezolana era Luisa Cáceres de Arismendi, que en realidad fue una víctima de su circunstancia y, sobre todo de su marido. Luisa Cáceres fue el ejemplo de la mujer dócil, que es arrastrada por los acontecimientos y que, para los esquemas antiguos era la mujer ideal: joven, hermosa, pasiva, discreta y, aparentemente sin opiniones. Josefa Camejo es, en estos nuevos tiempos, la nueva gran heroína venezolana: hay condecoraciones con su nombre, un aeropuerto, complejos culturales, comederos populares, plazas, avenidas, plantas de refinación, barrios, plantas termoeléctricas, cuevas, entre otras cosas. Lo preocupante es que lo único que se rescata de ella son sus acciones militares, no así su educación poco usual para la época, su determinación, que escribiera o que tuviera ideas.

En suma, las mujeres de antes, como las de ahora, construían el país y la idílica existencia de damas consentidas que se nos ha presentado no tiene mucho que ver con la realidad. Muchas de las interpretaciones históricas son discursos tradicionales, que tienen que ver con el poder. Ya Michel de Certau nos dijo que la historia es un discurso legitimador de los poderes instituidos. Así, en algún momento se decidió que las mujeres debían ser pasivas y tranquilas, en otro que sólo algunas deberían aparecer en los libros de historia, en otro que las que lo hicieran deberían tener características y virtudes especiales $^{21}$.

Pero, si durante años las mujeres desaparecieron del discurso histórico, cometiéndose una gran injusticia con ellas, es igualmente injusto que ahora aparezcan, pero dándole énfasis al aspecto heroico, pero no en el sentido de sus grandes virtudes sino en el de sus grandes hazañas en la guerra y olvidando el resto. Es como si, nuevamente, el discurso del poder nos dictara la pauta. Ahora es el de las hazañas militares, lo épico, lo epopéyico. En realidad, las hazañas civiles como construir una nación desde lo económico, educativo y social, que es lo que hicieron muchas mujeres como Josefa Camejo y Dominga Ortiz, era probablemente mucho más difícil y complicado que participar en una guerra. Ellas fueron unas heroínas civiles antes y después de la guerra, levantando hijos, haciendas, demandando sus derechos legales, cuidando de tierras, hombres y animales. Que además hayan participado en alguna batalla me parece pequeño, ante, como diría Mirla Alcibíades, la heroica aventura de construir un país ${ }^{22}$.

19 Ibid, p. 26.

20 IRIBARREN CELIS, Lino. "Investigaciones históricas. La heroína Josefa Camejo como figura del procerato venezolano de la Independencia”. En: Boletín de la Academia Nacional de la Historia, 165. Caracas, enero-marzo 1959, pp. 24-25.

${ }^{21}$ Sobre el héroe de la independencia y su mitificación (incluyendo el patriotismo hereditario) es interesante la posición de Veronique Hebrard. "El hombre en armas: de la heroización al mito". En: CARRERA, LEAL, LOMNÉ, MARTÍNEZ (ed) Mitos políticos en las sociedades andinas. Caracas: Equinoccio/Université de Marne-la-Vallée/Instituto Francés de Estudios Andinos, 2006, 286 y ss).

22 Uso aquí el título del libro de ALCIBÍADES, Mirla. La heroica aventura de construir una república. Familia-nación en el ochocientos venezolano (1830-1865). Caracas: Monte Avila/Celarg, 2004. 